\title{
The influence of sulforaphane on vascular health and its relevance to nutritional approaches to prevent cardiovascular disease
}

\author{
Paul C. Evans
}

Received: 22 December 2010 / Accepted: 17 January 2011 / Published online: 12 February 2011

(C) European Association for Predictive, Preventive and Personalised Medicine 2011

\begin{abstract}
Oxidation of low-density lipoproteins (LDL) promotes atherosclerosis by enhancing vascular inflammation and foam cell formation. The corollary is that diets that stimulate endogenous anti-oxidants may protect against atherosclerosis. This review focuses on sulforaphane, an isothiocyanate derived from green vegetables, which induces multiple anti-oxidant enzymes via activation of a transcription factor called Nrf2. Although studies of cultured cells and experimental animals revealed that sulforaphane can suppress inflammatory activation of vascular cells, the potential beneficial effects of sulforaphane in atherosclerosis have not been studied directly. A deeper understanding of vascular responses to sulforaphane may inform nutritional approaches to prevent vascular inflammation and atherosclerosis.
\end{abstract}

Keywords Preventative medicine - Cardiovascular .

Nutrition $\cdot$ Sulforaphane

\section{The influence of oxidants and antioxidants on the development of atherosclerosis}

Atherosclerosis is a lipid-driven chronic inflammatory disease [1-4] in which accumulation of cells, lipids and extracellular matrix in the wall of an artery can result in occlusion of the vessel lumen and lead to angina, heart attack or stroke. A critical step in lesion formation is the oxidation of LDL to generate a family of covalent

P. C. Evans $(\bowtie)$

British Heart Foundation, Cardiovascular Sciences Unit,

National Heart and Lung Institute, Imperial College London,

Hammersmith Campus, Du Cane Road,

London W12 ONN, UK

e-mail: paul.evans@imperial.ac.uk modifications. Oxidised LDL (oxLDL) particles influence atherosclerosis by altering the physiology of endothelial cells (EC), macrophages and other cell types. They promote the recruitment of leukocytes from the bloodstream to the arterial wall by triggering EC expression of adhesion proteins, chemokines and other pro-inflammatory molecules [5-7]. This process involves multiple inflammatory signalling events including induction of intracellular reactive oxygen species (ROS) [6, 8], activation of p38 and ERK MAP kinases [8-10], and activation of the transcription factors NF-kB $[6,11]$ and STAT3 [7]. Moreover, evidence from our group and others suggests that ROS promote inflammatory activation in part by inactivating enzymes that negatively regulate inflammatory pathways [12-14]. Induction of ROS by oxLDL can also induce EC apoptosis [15-17], and influence vascular tone through uncoupling of eNOS from nitric oxide production $[18,19]$. OxLDL can also influence the physiology of macrophages which recognise and internalise oxLDL via scavenger receptors (e.g. CD36, Scavenger Receptor class A (SRA)) [20-23]. Binding of oxLDL to CD36 or SRA initiates a signalling cascade that includes MAP kinase and NF-KB activation [20, 24-28], which drives expression of inflammatory genes. Although clearance of oxLDL by macrophages maintains vascular homeostasis by preventing oxLDL build up, persistent phagocytosis leads to accumulation of intracellular lipids. This process creates activated foam cells that drive atherogenesis by generating oxidant moieties, secreting proinflammatory proteins, expressing thrombogenic factors and releasing toxic lipids [2-4].

Biological antioxidants are broadly divided into direct and indirect antioxidants. Direct antioxidants either absorb free radicals (e.g. vitamin E) or transfer electrons in redoxexchange (e.g. vitamin C). Indirect antioxidants, primarily phytochemicals, alter cellular physiology by inducing anti- 
oxidant genes (e.g. heme oxygenase-1 (HO-1), ferritin, thioredoxin, thioredoxin reductase 1 , glutathione, superoxide dismutase). Given the central importance of oxidation in atherogenesis, it has been proposed that antioxidants may protect arteries from lesion formation [29-31]. There are several lines of evidence to support this idea: (1) epidemiological studies correlate the consumption of fruit and vegetables rich in anti-oxidants with protection from cardiovascular disease [29-31], (2) in vitro studies revealed that antioxidants exert "anti-atherogenic" effects including suppression of pro-inflammatory activation of EC [32-36] and macrophages [37-39] and inhibition of vascular smooth muscle cell (VSMC) proliferation [40, 41], (3) genetic deletion of antioxidant genes including hemoxygenase-1 (HO-1) [42] and glutathione peroxidase-1 [43] can enhance experimental atherosclerosis, while overexpression of $\mathrm{HO}-1$ [44], thioredoxin [45] or catalase [46] reduces lesion formation, (4) a polymorphism in the promoter of the (antioxidant) HO-1 gene is associated with elevated risk of coronary heart disease in man $[47,48]$. The potential utility of antioxidants as therapeutics for the prevention or treatment of atherosclerosis has received considerable attention. However, clinical trials of dietary supplementation with vitamin $\mathrm{E}$ did not reveal beneficial effects on cardiovascular health in the general population [30,31], but gave promising results in some groups of patients with enhanced oxidative load associated with existing coronary artery disease [49] or end-stage renal disease [50]. In view of the disappointing results of direct antioxidants in clinical trials, we suggest that therapeutic strategies aimed at inducing anti-oxidant enzymes indirectly may be more effective. This concept is consistent with studies of probucol, a drug with both lipidlowering and indirect anti-oxidant effects, which suppressed atherosclerosis in pre-clinical $[51,52]$ and clinical trials [53, 54]. Importantly, comparison of probucol with control derivatives that retain its anti-oxidant effects but not lipidlowering effects, indicate that probucol's atheroprotective activity is primarily due to induction of anti-oxidant enzymes in vascular cells [55].

\section{Sulforaphane is an indirect dietary antioxidant}

Sulforaphane is a biologically active dietary isothiocyanate that is derived from vegetables in the Brassica genus (e.g. broccoli, brussel sprouts, cauliflower, Pak Choi). Recent studies revealed that sulforaphane alters cellular physiology, at least in part, by functioning as an indirect anti-oxidant. This property of sulforaphane is mediated via activation of the transcription factor Nrf2 which is a central regulator of cellular redox [56, 57]. In unstimulated cells, $\mathrm{Nrf2}$ is suppressed by kelch-like ECH-associated protein 1 (Keap1) which targets it for ubiquitination and proteasomal processing. Nrf2 can be activated by sulforaphane and other physiological stimuli which disrupt Keap1-Nrf2 interactions leading to stabilisation and nuclear translocation of Nrf2 [56, 57] (Fig. 1). Following its activation, Nrf2 binds to electrophilic response elements (otherwise known as antioxidant response elements) and induces numerous antioxidants including HO-1, ferritin, thioredoxin, thioredoxin reductase 1 and MnSOD [56-59].

\section{The protective effects of sulforaphane on vascular physiology}

The concept that consumption of green vegetables can prevent cardiovascular disease is consistent with epidemiological studies that revealed that dietary intake of broccoli and related vegetables is associated with reduced risk of

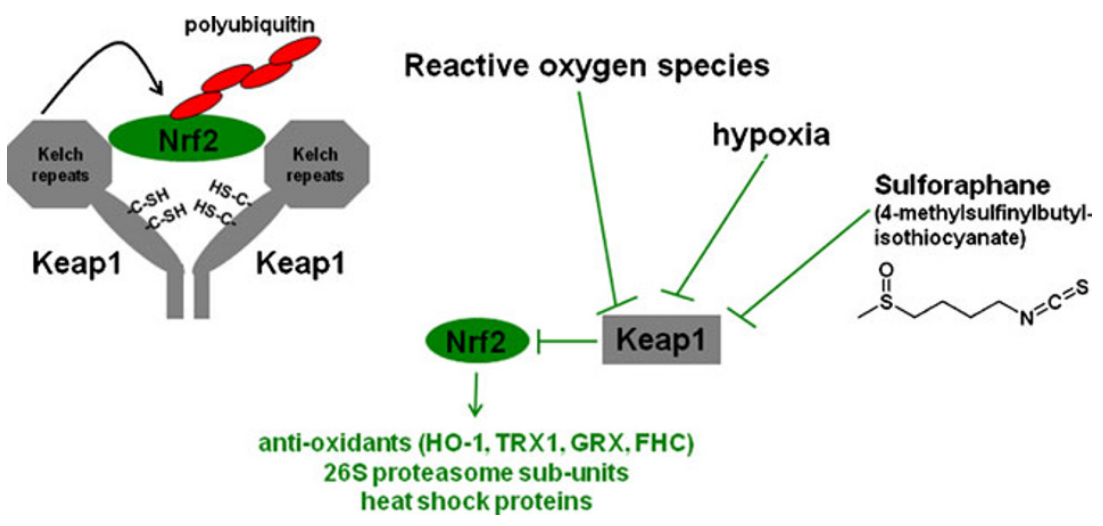

Fig. 1 Regulation and function of Nrf2. Nrf2 is a transcription factor that induces numerous antioxidants (e.g. hemoxygenase-1 (HO-1), thioredoxin (TRX1), ferritin heavy chain (FHC)), 26S proteasome subunits, heat shock proteins and other protective molecules. In unstimulated cells, Nrf2 is inactivated by Keap1 which sequesters
Nrf2 in the cytoplasm and targets Nrf2 for ubiquitination and degradation. Nrf2 can be activated by several stimuli (e.g. reactive oxygen species, hypoxia, sulforaphane) that interfere with Nrf2-Keap 1 interaction 
coronary heart disease mortality [60-63]. It also consistent with the observation that ingestion of broccoli can reduce oxidation and inflammation in arteries of spontaneously hypertensive stroke-prone rats [64]. Pharmacokinetic studies in humans that revealed that consumption of a single portion of broccoli cress (a particularly rich source of sulforaphane) or mature broccoli can generate plasma sulforaphane concentrations of approximately $1 \mu \mathrm{M}[65$, 66] and $60 \mathrm{nM}$ [67], respectively. Plasma sulforaphane concentrations subsequently declined with first-order kinetics ( $1.77 \mathrm{~h}$ half life) to reach low $\mathrm{nM}$ concentrations within several hours [65-67]. Although sulforaphane is rapidly cleared from plasma, it is plausible that it may have prolonged effects on vascular physiology as consumption of broccoli can induce antioxidant enzymes for at least $24 \mathrm{~h}$ in healthy volunteers $[68,69]$. In vitro studies revealed that concentrations of sulforaphane that can be achieved in plasma through consumption of Brassica vegetables can influence the physiology of vascular and inflammatory cells [70-75], suggesting that green vegetable intake may prevent cardiovascular disease in part via generation of sulforaphane.

We recently studied the effects of shear stress and sulforaphane on endothelial activation in aortae of mice challenged with lipopolysaccharide (LPS) [70]. Vascular inflammation and atherosclerosis develop predominantly at branches and bends of arteries which are exposed to nonuniform blood flow which exerts relatively low shear stress on vascular endothelium, whereas regions of arteries that are exposed to high shear stress are protected [76, 77]. Proinflammatory activation of EC is reduced at high shear sites compared to low shear regions, thus providing a potential explanation for the distinct spatial localisation of lesions $[70,78,79]$. Our findings revealed that high shear stress at atheroprotected sites reduced key measures of EC inflammatory activation, p38 MAP kinase activation and VCAM1 expression, by activating Nrf2 [70] (Fig. 2). By contrast, $\mathrm{EC}$ at a low shear, atherosusceptible site contained inactive (cytoplasmic) Nrf2 and were prone to pro-inflammatory activation. We therefore examined whether pharmacological activation of Nrf2 using sulforaphane would suppress inflammation at susceptible sites. In cultured EC, sulforaphane suppressed $\mathrm{p} 38$ activation, VCAM-1 expression and ROS production via Nrf2 [70, 71]. Similarly, sulforaphane suppressed p38 activation and VCAM-1 expression at atherosusceptible sites in wild-type but not in Nrf2-/- mice, indicating that the anti-inflammatory effects of sulforaphane were Nrf2-dependent [70] (Fig. 2). Thus our observations reveal that inflammation at atherosusceptible regions can be prevented by sulforaphane-mediated activation of Nrf2.

Given observations from our group and others that Nrf2 and its target genes can protect against vascular inflammation $[42,43,70]$ it would be expected that ablation of Nrf2 would exaggerate atherosclerosis. Consistent with this, Levonen et al. demonstrated that Nrf2 overexpression in the rabbit aorta reduces inflammation in response to injury [80]. However, paradoxically, a recent report points in the opposite direction, with genetic deletion of Nrf2 suppressing CD36-dependent uptake of modified LDL by macrophages and reducing lesion development in an atherosusceptible strain of mice [81]. This latter study does not however preclude a protective role for $\mathrm{Nrf} 2$ during the initiation of atherosclerosis because: (1) early stages of atherogenesis were not studied, (2) the model studied is severe and any protective effects of Nrf2 may have been overwhelmed by the high atherogenic drive. Similarly, although sulforaphane can protect arteries from inflammation, this compound may have deleterious effects on vascular health at high concentrations, e.g. although low concentrations $(<1 \mu \mathrm{M})$ of sulforaphane can reduce inflammatory activation of $\mathrm{EC}$ without altering viability $[70,71]$, very high concentrations $(>10 \mu \mathrm{M})$ can trigger EC apoptosis [82-84]. High concentrations of sulforaphane can also induce CD36 in macrophages [85] and therefore may potentially influence the formation of foam cells which play

\section{ATHEROPROTECTED SITE}

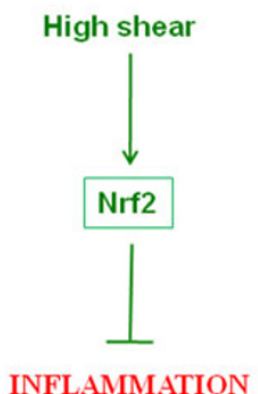

Fig. 2 Model-Consumption of Brassica vegetables may prevent vascular inflammation at atherosusceptible sites. Regions of arteries with relatively uniform geometry are protected from inflammation and atherosclerosis by high shear stress which activates Nrf2. By contrast,

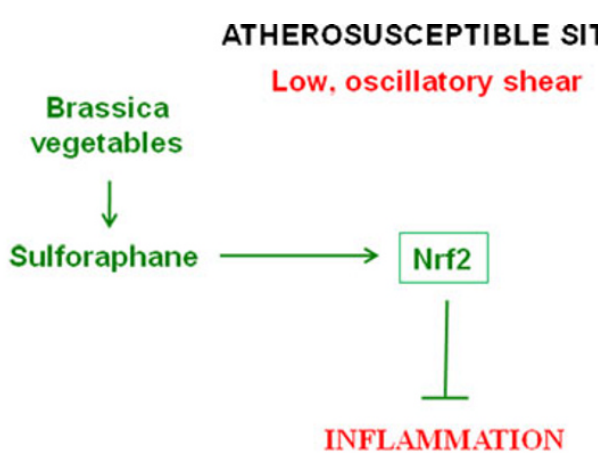

branches and bends that are exposed to low, oscillatory shear stress are susceptible to lesion formation. However, dietary consumption of Brassica vegetables may prevent branches and bends from inflammation by activating Nrf2 in endothelial cells 
a central role in atherogenesis. Thus it will be important in future studies to assess directly whether relatively low concentrations of sulforaphane (achievable through consumption of green vegetables) can prevent atherosclerosis, without triggering potential deleterious effects on EC viability.

\section{Outlook}

There is now strong evidence to suggest that regular consumption of Brassica vegetables may provide a preventative dietary approach to reduce cardiovascular disease risk. This has been obtained partly through epidemiological studies that correlated green vegetable intake with protection. The idea is also consistent with the observation that plasma concentrations of sulforaphane that can be achieved by consumption of green vegetables are sufficient to suppress inflammatory activation of arteries. Clinical trials should now be carried out to test directly whether consumption of green vegetables or bioactive derivatives (e.g. sulforaphane) can prevent the initiation and progression of atherosclerosis. This idea is currently being pursued through a study that will investigate the effects of a diet rich in broccoli on plasma cholesterol levels, blood pressure and augmentation index and pulse wave velocity (measures of arterial stiffness) in subjects with elevated cardiovascular risk (ClinicalTrials.gov identifier NCT01114399). In addition to their scientific value, trials of this nature may also provide value in terms of public perception by reinforcing guidelines that eating fruit and vegetables can prevent cardiovascular disease.

\section{References}

1. Badimon L, Vilahur G, Padro T. Nutraceuticals and atherosclerosis: human trials. Cardiovasc Ther. 2010;28:202-15.

2. Libby P. Inflammation in atherosclerosis. Nature. 2002;420:86874.

3. Glass CK, Witztum JL. Atherosclerosis. The road ahead. Cell. 2001;104:503-16.

4. Galkina E, Ley K. Immune and inflammatory mechanisms of atherosclerosis. Annu Rev Immunol. 2009;27:165-97.

5. Yeh M, Leitinger N, de Martin R, et al. Increased transcription of IL-8 in endothelial cells is differentially regulated by TNF-alpha and oxidized phospholipids. Arterioscler Thromb Vasc Biol. 2001;21:1585-91.

6. Cominacini L, Pasini AF, Garbin U, et al. Oxidized low density lipoprotein (ox-LDL) binding to ox-LDL receptor-1 in endothelial cells induces the activation of NF-kappa B through an increased production of intracellular reactive oxygen species. J Biol Chem. 2000;275:12633-8.

7. Yeh M, Gharavi NM, Choi J, et al. Oxidized phospholipids increase interleukin 8 (IL-8) synthesis by activation of the c-src/signal transducers and activators of transcription (STAT) 3 pathway. J Biol Chem. 2004;279:30175-81.
8. Lin SJ, Shyue SK, Liu RL, et al. Adenovirus-mediated overexpression of catalase attenuates oxLDL-induced apoptosis in human aortic endothelial cells via AP-1 and C-Jun N-terminal kinase/ extracellular signal-regulated kinase mitogen-activated protein kinase pathways. J Mol Cell Cardiol. 2004;36:129-39.

9. Huber J, Furnkranz A, Bochkov VN, et al. Specific monocyte adhesion to endothelial cells induced by oxidized phospholipids involves activation of $\operatorname{cPLA}(2)$ and lipoxygenase. J Lipid Res. 2006;47:1054-62.

10. Mattaliano MD, Huard C, Cao W, et al. LOX-1-dependent transcriptional regulation in response to oxidized LDL treatment of human aortic endothelial cells. Am J Physiol Cell Physiol. 2009;296:C1329-37.

11. Li DY, Mehta JL. Upregulation of endothelial receptor for oxidized LDL (LOX-1) by oxidized LDL and implications in apoptosis of human coronary artery endothelial cells - evidence from use of antisense LOX-1 mRNA and chemical inhibitors. Arterioscler Thromb Vasc Biol. 2000;20:1116-22.

12. Kamata H, Honda S, Maeda S, Chang LF, Hirata H, Karin M. Reactive oxygen species promote TNF alpha-induced death and sustained JNK activation by inhibiting MAP kinase phosphatases. Cell. 2005;120:649-61.

13. Enesa K, Ito K, Luong LA, et al. Hydrogen peroxide prolongs nuclear localization of NF-kappa B in activated cells by suppressing negative regulatory mechanisms. J Biol Chem. 2008;283:18582-90.

14. Ito K, Hanazawa T, Tomita K, Barnes PJ, Adcock IM. Oxidative stress reduces histone deacetylase 2 activity and enhances IL8 gene expression: role of tyrosine nitration. Biochem Biophys Res Commun. 2004;315:240-5.

15. Dimmeler S, Haendeler J, Galle J, Zeiher AM. Oxidized lowdensity lipoprotein induces apoptosis of human endothelial cells by activation of CPP32-like proteases - a mechanistic clue to the 'response to injury' hypothesis. Circulation. 1997;95:1760-3.

16. Foteinos G, Hu YH, Xiao QZ, Metzler B, Xu QB. Rapid endothelial turnover in atherosclerosis-prone areas coincides with stem cell repair in apolipoprotein E-deficient mice. Circulation. 2008;117:1856-63.

17. Stoneman VEA, Bennett MR. Role of apoptosis in atherosclerosis and its therapeutic implications. Clin Sci. 2004;107:343-54.

18. Cosentino F, Hurlimann D, Gatti CD, et al. Chronic treatment with tetrahydrobiopterin reverses endothelial dysfunction and oxidative stress in hypercholesterolaemia. Heart. 2008;94:487-92.

19. Crabtree MJ, Tatham AL, Hale AB, Alp NJ, Channon KM. Critical role for tetrahydrobiopterin recycling by dihydrofolate reductase in regulation of endothelial nitric-oxide synthase coupling: relative importance of the denovo biopterin synthesis versus salvage pathways. J Biol Chem. 2009;284:28128-36.

20. Maziere C, Maziere JC. Activation of transcription factors and gene expression by oxidized low-density lipoprotein. Free Radic Biol Med. 2009;46:127-37.

21. Ishigaki Y, Oka Y, Katagiri H. Circulating oxidized LDL: a biomarker and a pathogenic factor. Curr Opin Lipidol. 2009;20:363-9.

22. Schmitz G, Grandl M. Role of redox regulation and lipid rafts in macrophages during Ox-LDL-mediated foam cell formation. Antioxid Redox Signal. 2007;9:1499-518.

23. Collot-Teixeira S, Martin J, Dennott-Roe C, Poston R, McGregor JL. CD36 and macrophages in atherosclerosis. Cardiovasc Res. 2007;75:468-77.

24. Rahaman SO, Lennon DJ, Febbraio M, Podrez EA, Hazen SL, Silverstein RL. A CD36-dependent signaling cascade is necessary for macrophage foam cell formation. Cell Metab. 2006;4:211-21.

25. Janabi M, Yamashita S, Hirano K, et al. Oxidized LDL-induced NF-kappa B activation and subsequent expression of proinflammatory genes are defective in monocyte-derived macrophages 
from CD36-deficient patients. Arterioscler Thromb Vasc Biol. 2000;20:1953-60.

26. Hakala JK, Lindstedt KA, Kovanen PT, Pentikainen MO. Lowdensity lipoprotein modified by macrophage-derived lysosomal hydrolases induces expression and secretion of IL-8 via p38 MAPK and NF-kappa B by human monocyte-derived macrophages. Arterioscler Thromb Vasc Biol. 2006;26:2504-9.

27. Kusuhara M, Chait A, Cader A, Berk BC. Oxidized LDL stimulates mitogen-activated protein kinases in smooth muscle cells and macrophages. Arterioscler Thromb Vasc Biol. 1997;17:141-8.

28. Jovinge S, Ares MPS, Kallin B, Nilsson J. Human monocytes/ macrophages release TNF-alpha in response to Ox-LDL. Arterioscler Thromb Vasc Biol. 1996;16:1573-9.

29. Kris-Etherton PM, Lichtenstein AH, Howard BV, Steinberg D, Witztum JL. Antioxidant vitamin supplements and cardiovascular disease. Circulation. 2004;110:637-41.

30. Katsiki N, Manes C. Is there a role for supplemented antioxidants in the prevention of atherosclerosis? Clin Nutr. 2009;28:3-9.

31. Willcox BJ, Curb JD, Rodriguez BL. Antioxidants in cardiovascular health and disease: key lessons from epidemiologic studies. Am J Cardiol. 2008;101:75D-86D.

32. Marui N, Offermann MK, Swerlick R, et al. Vascular celladhesion molecule-1 (Vcam-1) gene-transcription and expression are regulated through an antioxidant sensitive mechanism in human vascular endothelial-cells. J Clin Invest. 1993;92:1866-74.

33. Kaneko M, Hayashi J, Saito I, Miyasaka N. Probucol downregulates E-selectin expression on cultured human vascular endothelial cells. Arterioscler Thromb Vasc Biol. 1996;16:104751

34. Bowie AG, O'Neill LAJ. Vitamin C inhibits NF-kappa B activation by TNF via the activation of $\mathrm{p} 38$ mitogen-activated protein kinase. J Immunol. 2000;165:7180-8.

35. Chen JW, Lin FY, Chen YH, Wu TC, Chen YL, Lin SJ. Carvedilol inhibits tumor necrosis factor-alpha-induced endothelial transcription factor activation, adhesion molecule expression, and adhesiveness to human mononuclear cells. Arterioscler Thromb Vasc Biol. 2004;24:2075-81.

36. Carcamo JM, Pedraza A, Borquez-Ojeda O, Golde DW. Vitamin C suppresses TNF alpha-induced NF kappa B activation by inhibiting I kappa B alpha phosphorylation. Biochemistry. 2002;41:12995-3002.

37. Fox ES, Brower JS, Bellezzo JM, Leingang KA. N-acetylcysteine and alpha-tocopherol reverse the inflammatory response in activated rat Kupffer cells. J Immunol. 1997;158:5418-23.

38. Victor VM, De La Fuente M. N-acetylcysteine improves in vitro the function of macrophages from mice with endotoxin-induced oxidative stress. Free Radic Res. 2002;36:33-45.

39. Carcamo J, Borquez-Ojeda O, Golde D. Vitamin C inhibits granulocyte macrophage-colony-stimulating factor-induced signaling pathways. Blood. 2002;99:3205-12.

40. Lee KH, Lim SY, Kang SM, et al. Antiproliferative mechanisms of raxofelast (IRFI-016) in $\mathrm{H} 2 \mathrm{O} 2$-stimulated rat aortic smooth muscle cells. Eur J Pharmacol. 2004;484:119-25.

41. Konneh MK, Rutherford C, Li SR, Anggard EE, Ferns GAA. Vitamin-e inhibits the intimal response to balloon catheter injury in the carotid-artery of the cholesterol-fed rat. Atherosclerosis. 1995;113:29-39.

42. Orozco LD, Kapturczak MH, Barajas B, et al. Heme oxygenase-1 expression in macrophages plays a beneficial role in atherosclerosis. Circ Res. 2007;100:1703-11.

43. Lewis P, Stefanovic N, Pete J, et al. Lack of the antioxidant enzyme glutathione peroxidase-1 accelerates atherosclerosis in diabetic apolipoprotein E-deficient mice. Circulation. 2007;115:2178-87.

44. Juan SH, Lee TS, Tseng KW, et al. Adenovirus-mediated heme oxygenase- 1 gene transfer inhibits the development of atheroscle- rosis in apolipoprotein E-deficient mice. Circulation. 2001;104:1519-25

45. Zhang HF, Luo Y, Zhang W, et al. Endothelial-specific expression of mitochondrial thioredoxin improves endothelial cell function and reduces atherosclerotic lesions. Am J Pathol. 2007;170:1108-20.

46. Yang H, Roberts LJ, Shi MJ, et al. Retardation of atherosclerosis by overexpression of catalase or both $\mathrm{Cu} / \mathrm{Zn}$-superoxide dismutase and catalase in mice lacking apolipoprotein E. Circ Res. 2004;95:1075-81.

47. Kaneda H, Ohno M, Taguchi J, et al. Heme oxygenase-1 gene promoter polymorphism is associated with coronary artery disease in Japanese patients with coronary risk factors. Arterioscler Thromb Vasc Biol. 2002;22:1680-5.

48. Chen YH, Lin SJ, Lin MW, et al. Microsatellite polymorphism in promoter of heme oxygenase-1 gene is associated with susceptibility to coronary artery disease in type 2 diabetic patients. Hum Genet. 2002;111:1-8.

49. Stephens NG, Parsons A, Schofield PM, et al. Randomised controlled trial of vitamin $\mathrm{E}$ in patients with coronary disease: Cambridge Heart Antioxidant Study (CHAOS). Lancet. 1996;347:781-6.

50. Boaz M, Smetana S, Weinstein T, et al. Secondary prevention with antioxidants of cardiovascular disease in endstage renal disease (SPACE): randomised placebo-controlled trial. Lancet. 2000;356:1213-8.

51. Witting PK, Pettersson K, Letters J, Stocker R. Site-specific antiatherogenic effect of probucol in apolipoprotein E-deficient mice. Arterioscler Thromb Vasc Biol. 2000;20:E26-33.

52. Schneider JE, Berk BC, Gravanis MB, et al. Probucol decreases neointimal formation in a swine model of coronary-artery balloon injury - a possible role for antioxidants in restenosis. Circulation. 1993;88:628-37.

53. Tardif JC, Cote G, Lesperance J, et al. Probucol and multivitamins in the prevention of restenosis after coronary angioplasty. N Engl J Med. 1997;337:365-72.

54. Sawayama Y, Shimizu C, Maeda N, et al. Effects of Probucol and pravastatin on common carotid atherosclerosis in patients with asymptomatic hypercholesterolemia-Fukuoka Atherosclerosis Trial (FAST). J Am Coll Cardiol. 2002;39:610-6.

55. Wu BJ, Kathir K, Witting PK, et al. Antioxidants protect from atherosclerosis by a heme oxygenase-1 pathway that is independent of free radical scavenging. J Exp Med. 2006;203:1117-27.

56. Thimmulappa RK, Mai KH, Srisuma S, Kensler TW, Yamamato $\mathrm{M}$, Biswal S. Identification of Nrf2-regulated genes induced by the chemopreventive agent sulforaphane by oligonucleotide microarray. Cancer Res. 2002;62:5196-203.

57. Xue MZ, Qian QW, Adaikalakoteswari A, Rabbani N, BabaeiJadidi R, Thornalley PJ. Activation of NF-E2-related factor-2 reverses biochemical dysfunction of endothelial cells induced by hyperglycemia linked to vascular disease. Diabetes. 2008;57:2809-17.

58. Itoh $\mathrm{K}$, Chiba $\mathrm{T}$, Takahashi $\mathrm{S}$, et al. An Nrf2 small Maf heterodimer mediates the induction of phase II detoxifying enzyme genes through antioxidant response elements. Biochem Biophys Res Commun. 1997;236:313-22.

59. Kensler TW, Wakabayash N, Biswal S. Cell survival responses to environmental stresses via the Keap1-Nrf2-ARE pathway. Annu Rev Pharmacol Toxicol. 2007;47:89-116.

60. Yochum L, Kushi LH, Meyer K, Folsom AR. Dietary flavonoid intake and risk of cardiovascular disease in postmenopausal women. Am J Epidemiol. 1999;149:943-9.

61. Genkinger JM, Platz EA, Hoffman SC, Comstock GW, Helzlsouer KJ. Fruit, vegetable, and antioxidant intake and all-cause, cancer, and cardiovascular disease mortality in a community-dwelling population in Washington County, Maryland. Am J Epidemiol. 2004;160:1223-33. 
62. Hung HC, Joshipura KJ, Jiang R, et al. Fruit and vegetable intake and risk of major chronic disease. J Natl Cancer Inst. 2004;96:1577-84.

63. Cornelis MC, El-Sohemy A, Campos H. GSTT1 genotype modifies the association between cruciferous vegetable intake and the risk of myocardial infarction. Am J Clin Nutr. 2007;86:752-8.

64. Wu LY, Ashraf MHN, Facci M, et al. Dietary approach to attenuate oxidative stress, hypertension, and inflammation in the cardiovascular system. Proc Natl Acad Sci USA. 2004;101:7094-9.

65. Riedl MA, Saxon A, Diaz-Sanchez D. Oral sulforaphane increases Phase II antioxidant enzymes in the human upper airway. Clin Immunol. 2009;130:244-51.

66. Ye LX, Dinkova-Kostova AT, Wade KL, Zhang YS, Shapiro TA, Talalay P. Quantitative determination of dithiocarbamates in human plasma, serum, erythrocytes and urine: pharmacokinetics of broccoli sprout isothiocyanates in humans. Clin Chim Acta. 2002;316:43-53.

67. Hanlon N, Coldham N, Gielbert A, Sauer MJ, Ioannides C. Repeated intake of broccoli does not lead to higher plasma levels of sulforaphane in human volunteers. Cancer Lett. 2009;284:15-20.

68. Yanaka A, Fahey JW, Fukumoto A, et al. Dietary sulforaphane-rich broccoli sprouts reduce colonization and attenuate gastritis in helicobacter pylori-infected mice and humans. Cancer Prev Res. 2009;2:353-60.

69. Myzak MC, Tong P, Dashwood WM, Dashwood RH, Ho E. Sulforaphane retards the growth of human PC-3 xenografts and inhibits HDAC activity in human subjects. Exp Biol Med. 2007;232:227-34.

70. Zakkar M, Van der Heiden K, Luong LA, et al. Activation of nrf2 in endothelial cells protects arteries from exhibiting a proinflammatory state. Arterioscler Thromb Vasc Biol. 2009;29:1851-7.

71. Chen XL, Dodd G, Kunsch C. Sulforaphane inhibits TNF-alphainduced activation of p38 MAP kinase and VCAM-1 and MCP-1 expression in endothelial cells. Inflamm Res. 2009;58:513-21.

72. Zhu H, Jia Z, Strobl JS, Ehrich M, Misra HP, Li Y. Potent induction of total cellular and mitochondrial antioxidants and phase 2 enzymes by cruciferous sulforaphane in rat aortic smooth muscle cells: cytoprotection against oxidative and electrophilic stress. Cardiovasc Toxicol. 2008;8:115-25.

73. Wu L, Juurlink BH. The impaired glutathione system and its upregulation by sulforaphane in vascular smooth muscle cells from spontaneously hypertensive rats. J Hypertens. 2001;19:1819-25.
74. Liu YC, Hsieh CW, Weng YC, Chuang SH, Hsieh CY, Wung BS. Sulforaphane inhibition of monocyte adhesion via the suppression of ICAM-1 and NF-kappaB is dependent upon glutathione depletion in endothelial cells. Vascul Pharmacol. 2008;48:54-61.

75. Guerrero-Beltrán CE, Calderón-Oliver M, Pedraza-Chaverri J, Chirino YI. Protective effect of sulforaphane against oxidative stress: Recent advances. Exp Toxicol Pathol. 2010; doi:10.1016/j. etp.2010.11.005.

76. Davies PF. Endothelial mechanisms of flow-mediated atheroprotection and susceptibility. Circ Res. 2007;101:10-2.

77. Suo J, Ferrara DE, Sorescu D, Guldberg RE, Taylor WR, Giddens DP. Hemodynamic shear stresses in mouse aortas - implications for atherogenesis. Arterioscler Thromb Vasc Biol. 2007;27:346-51.

78. Zakkar M, Chaudhury H, Sandvik G, et al. Increased endothelial mitogen-activated protein kinase phosphatase-1 expression suppresses proinflammatory activation at sites that are resistant to atherosclerosis. Circ Res. 2008;103:726-32.

79. Dai GH, Kaazempur-Mofrad MR, Natarajan S, et al. Distinct endothelial phenotypes evoked by arterial waveforms derived from atherosclerosis-susceptible and -resistant regions of human vasculature. Proc Natl Acad Sci USA. 2004;101:14871-6.

80. Levonen $\mathrm{AL}$, Inkala $\mathrm{M}$, Heikura $\mathrm{T}$, et al. Nrf2 gene transfer induces antioxidant enzymes and suppresses smooth muscle cell growth in vitro and reduces oxidative stress in rabbit aorta in vivo. Arterioscler Thromb Vasc Biol. 2007;27:741-7.

81. Sussan TE, Jun J, Thimmulappa R, et al. Disruption of Nrf2, a key inducer of antioxidant defenses, attenuates ApoE-mediated atherosclerosis in mice. PLoS ONE. 2008;3:e3791.

82. Nishikawa T, Tsuno NH, Okaji Y, et al. The inhibition of autophagy potentiates anti-angiogenic effects of sulforaphane by inducing apoptosis. Angiogenesis. 2010;13:227-38.

83. Nishikawa $\mathrm{T}$, Tsuno NH, Tsuchiya $\mathrm{T}$, et al. Sulforaphane stimulates activation of proapoptotic protein bax leading to apoptosis of endothelial progenitor cells. Ann Surg Oncol. 2009;16:534-43.

84. Asakage M, Tsuno NH, Kitayama J, et al. Sulforaphane induces inhibition of human umbilical vein endothelial cells proliferation by apoptosis. Angiogenesis. 2006;9:83-91.

85. Maruyama A, Tsukamoto S, Nishikawa K, et al. Nrf2 regulates the alternative first exons of CD36 in macrophages through specific antioxidant response elements. Arch Biochem Biophys. 2008;477:139-45. 